'Breeding for Success: Diversity in Action' C.F. Mercer (ed).

Proceedings of the $13^{\text {th }}$ Australasian Plant Breeding Conference,

Christchurch, New Zealand 18-21 April 2006. pp. 330-338.

\title{
Use of bulk hybrid populations to select for adaptation to contrasting environments in subterranean clover
}

\author{
Phillip Nichols $^{1,2,3}$ and Philip Cocks ${ }^{2,3}$ \\ ${ }^{1}$ Department of Agriculture Western Australia, Locked Bag 4, Bentley Delivery Centre \\ WA 6983, Australia \\ ${ }^{2}$ School of Plant Biology, University of Western Australia, 35 Stirling Highway, \\ Crawley WA 6009, Australia \\ ${ }^{3}$ Centre for Legumes in Mediterranean Agriculture, University of Western Australia, 35 \\ Stirling Highway, Crawley WA 6009, Australia
}

Abstract. Population changes were measured over 17 years within a highly variable bulk hybrid population of subterranean clover in a short and long growing season mediterranean-type environment in Western Australia. Flowering time was used as an indicator of evolutionary change and was highly responsive to environment. Markedly different populations evolved, with rapid selection for early flowering at the short growing season site and later flowering at the long growing season site.

The use of bulk hybrid populations is suggested as a low-input means of breeding and selecting annual pasture legumes adapted to target environments and farming systems. While adapted genotypes can be selected after just 3 seasons, further adaptive fine-tuning occurs with increased homozygosity. The success of the method hinges on the original parents containing genes for desirable characters, trial sites being representative of target environments and trial management being representative of typical farm practice.

\section{Introduction}

Subterranean clover (Trifolium subterraneum L.) is a predominantly self-pollinated, diploid species $(2 n=16)$. It is the most widely sown annual pasture legume in Australia, having been sown over an estimated area of 22 million ha (Sandral et al. 1997). It is a long-day plant adapted to the winter growing season of the mediterranean-type climate of southern Australia and is reliant on self-regeneration for persistence. There are 2 keys to its widespread use. One is its tolerance of heavy grazing, largely attributable to its prostrate growth habit and its ability to protect against seed predation by burial of its burrs. The other is a range of cultivars which differ in flowering time, enabling it to be grown in environments with growing season lengths from 4 to 9 months. To date 41 cultivars have been released in Australia (Nichols et al. 1996, Nichols, unpub. data) and there is an active breeding program as part of the National Annual Pasture Legume Improvement Program.

Suneson (1956) first described the bulk hybrid plant breeding method for barley, in which seed bulked from a set of crosses, was harvested and re-sown over a number of generations. Allard (1988) reports cumulative increases in reproductive capacity over 60 generations in one such barley bulk hybrid population. Subterranean clover would appear to be even better suited to use of such a breeding method than barley, particularly when plots are allowed to regenerate naturally from seed set, rather than repeatedly harvested and re-sown. It has a similar breeding system to barley, but as a self-regenerating annual, is reliant on seed production for persistence between seasons. 
Flowering time is the most responsive to environmental change of all reproductive strategies practiced by mediterranean annual plants (Ehrman and Cocks 1996). Timing of flowering is a balance between remaining vegetative for long enough to maximise accumulation of biomass and compete for light with other genotypes, and maturing early enough to enable adequate seed production prior to the onset of summer drought. Several ecotype studies (Piano 1984, Piano et al. 1993, 1996, Pecetti and Piano 2002) have shown that plants collected from short growing season environments tend to flower earlier than those from long growing season environments.

This paper examines evolution over 17 years in a complex bulk hybrid subterranean clover population at two contrasting sites in Western Australia, using changes in flowering time as an indicator of evolutionary change. It is the first bulk hybrid population study published for subterranean clover or any other pasture legume species. It is also the first report for any species of evolution in a bulk hybrid population sown at different sites.

\section{Materials and methods}

The original bulk hybrid population consisted of $\mathrm{F}_{2}$ seed derived from 253 crosses (Nichols 2004). It was sown at both Mount Barker Research Station ( $34^{\circ} 38^{\prime} \mathrm{S}, 117^{\circ}$ $\left.33^{\prime} \mathrm{E}\right), 350 \mathrm{~km}$ south of Perth, and Chapman Research Station, Nabawa (28 $30^{\circ} \mathrm{S}, 114^{\circ}$ $\left.47^{\prime} \mathrm{E}\right), 470 \mathrm{~km}$ north of Perth, chosen to represent long and short growing season environments, respectively. The long-term mean annual rainfall at Nabawa is $454 \mathrm{~mm}$ and at Mt Barker is $743 \mathrm{~mm}$. Mean annual maximum temperatures are $26.4{ }^{\circ} \mathrm{C}$ and 20.1 ${ }^{\circ} \mathrm{C}$ for Nabawa and Mt Barker, respectively. Both sites were selected on the basis of low background clover seed banks.

Trial sites were sown in 1978 on 17 May at Mt Barker, and on 1 June at Nabawa. Both occupied 0.4 ha. Seed was drilled in at a rate of $25 \mathrm{~kg} / \mathrm{ha}$ with $165 \mathrm{~kg} / \mathrm{ha}$ of plain superphosphate. Plain superphosphate was also applied each successive autumn at a rate of $100 \mathrm{~kg} / \mathrm{ha}$. Trials were fenced but grazing was conducted by sheep in conjunction with the surrounding paddock. Accurate grazing records were not kept, but management approximated local district practices, consisting of a mixture of set stocking and rotational grazing. All plant residues were removed by heavy grazing in early summer. In 1991 and 1994 the Nabawa site was cropped to wheat, while the Mt Barker site was cropped to oats. Subterranean clover germinating in these years was killed by cultivation and herbicides.

A soil moisture balance model, using weekly rainfall recordings and long-term mean weekly evaporation (Epan) levels, was constructed for Nabawa and Mt Barker to estimate growing season length and time to onset of soil water deficit in spring. A maximum soil water holding capacity of $75 \mathrm{~mm}$ was used for both sites. Weekly soil moisture balance was calculated as the cumulative difference between rainfall input and an indexed evaporative loss of $1.21 \times$ Epan $^{0.75}$ (Prescott 1934).

Seed samples were collected from both sites each summer following pasture senescence. Samples were taken of seed produced in the growing seasons from 1980 to 1994 , except for the cropped year of 1991. They consisted of 20 random quadrats, each of $20 \mathrm{dm}^{2}$, dug to a depth of approximately $5 \mathrm{~cm}$. Samples were sieved in a $1.5 \mathrm{~mm}$ sieve to remove excess soil, bulked and the seed mechanically threshed from burrs. Debris was removed by hand-sorting. Clean seed samples were weighed, dried, sealed in aluminium foil packets and maintained at $4^{\circ} \mathrm{C}$. A sample of the original bulk hybrid population was also stored. 
Examination of populations was conducted in 1995 at the University of Western Australia Field Station, Shenton Park ( $31^{\circ} 57^{\prime}$ S, $\left.115^{\circ} 50^{\prime} \mathrm{E}\right)$. Seeds sampled from Nabawa and Mt Barker were sown in a glasshouse at Shenton Park on 15 May. A sample of the original bulk hybrid population was also included in the study. All populations from Nabawa and Mt Barker had at least 70 per cent viability, while the original bulk hybrid population had only 33 per cent viability. Random sub-samples of 140 scarified seeds of the Nabawa and Mt Barker populations and 280 seeds of the original population were sown into hydrated peat pots. Group C Rhizobial inoculum was applied 3 days after sowing. Peat pots were watered daily and soluble fertiliser (Phosphogen at a rate of 5 grams/10 L) was applied weekly. Fifty four random seedlings of each population were transplanted into the field, 43 days after sowing. Fertiliser (100 kg/ha of 3:1 super potash) was drilled in and was also applied by hand at the same rate on 24 September. The trial site was hand weeded and irrigated by overhead sprinklers as required.

Flowering time was measured as the number of days from sowing to appearance of the first flower. Plants were checked every 3-4 days. Student's t-tests were used to compare population differences, while trends over time were measured by linear regression. Pearson correlations were conducted to examine relationships between flowering time and environmental variables. Statistical analyses were conducted using SYSTAT for Windows, Version 5.

\section{Results}

$\underline{\text { Rainfall and growing seasons at bulk hybrid sites }}$

Mean annual rainfall between 1978 and 1994 was lower than the long-term average at both sites. At Mt Barker mean rainfall was $669 \mathrm{~mm}$ and mean growing season length was 31.3 weeks. This compares with $432 \mathrm{~mm}$ mean annual rainfall and 19.4 weeks mean growing season length at Nabawa.

Total seed banks at Nabawa and Mt Barker

Figure 1 shows the total subterranean clover seed bank at both sites for the 16 years from 1978. Seed production was poor in the establishment year at both sites and continued to be poor for the following 2 seasons at Nabawa. Excluding the establishment year, seed banks over the remaining trial period averaged $940 \mathrm{~kg} / \mathrm{ha}$ at $\mathrm{Mt}$ Barker and $155 \mathrm{~kg} / \mathrm{ha}$ at Nabawa. There were no significant correlations of seed bank size with either annual rainfall, growing season length or May-October rainfall at either site for the whole trial or for Years 4-16. 


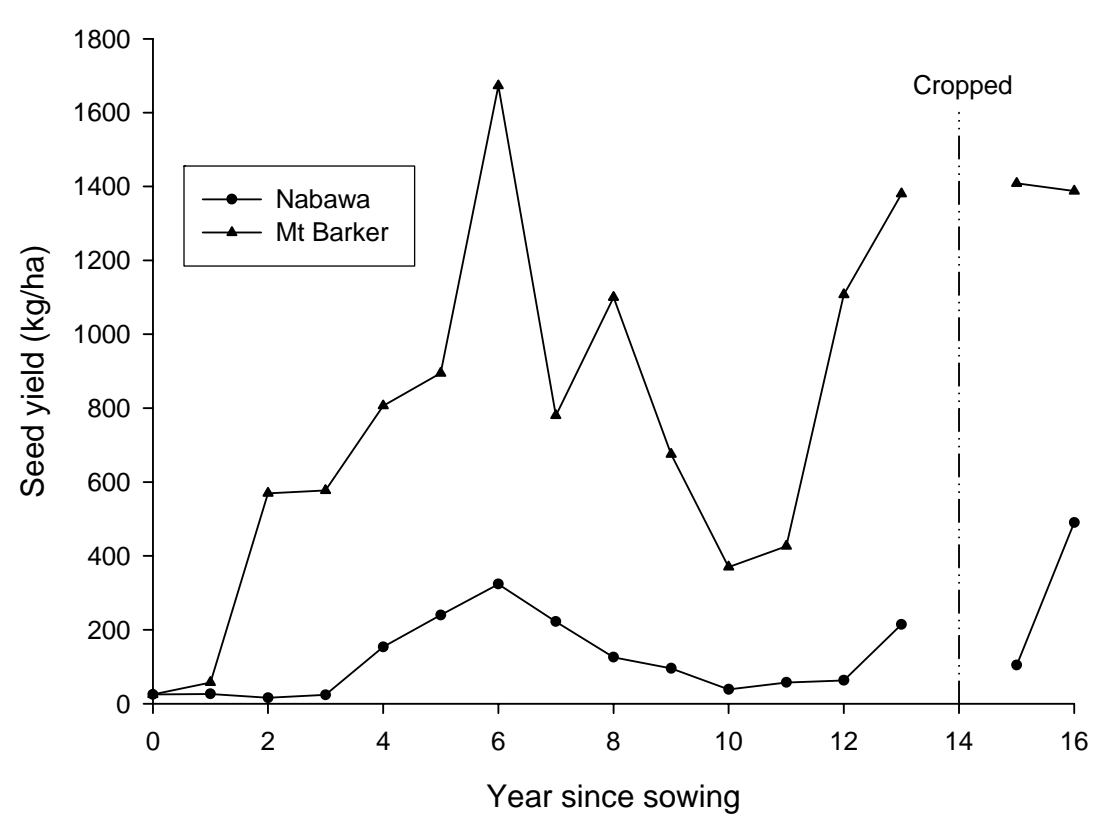

Figure 1. Annual seed bank (bulked samples) of a bulk hybrid population sown at Nabawa and Mt Barker in 1978. Seed samples were not taken in 1991 (Year 14) following a year in crop.

Changes in flowering time

The original bulk hybrid population was highly variable for days to first flowering (DFF). After just 3 seasons mean DFF of plants from the 2 sites differed significantly from both the original bulk hybrid population $(\mathrm{P} \leq 0.001)$ and from each other $(\mathrm{P} \leq$ 0.001) (Figure 2). Mean flowering time of the Nabawa populations from 1980-1994 (84.3 days) was 30 days earlier than those from Mt Barker (114.7 days), with the original bulk hybrid population having a mean flowering time intermediate to both (100.6 days). 


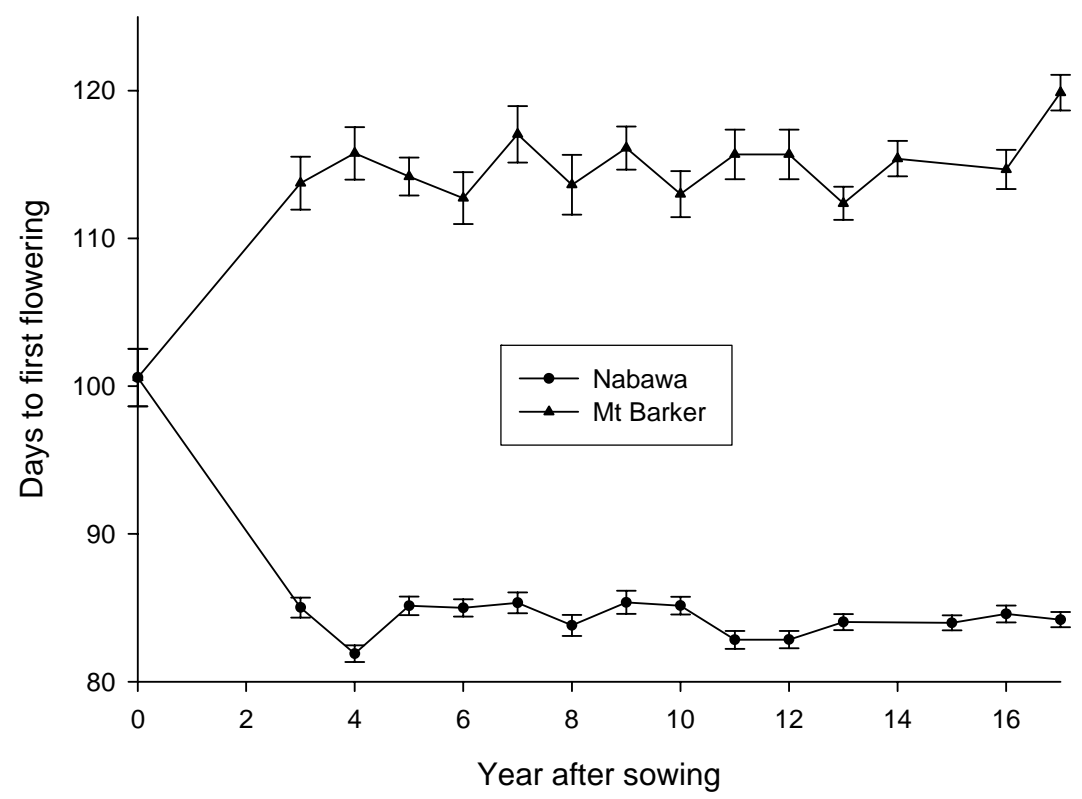

Figure 2. Mean days to first flowering (with standard errors) at Shenton Park in 1995 from seed sampled each year from a bulk hybrid population sown in 1978 at Nabawa and Mt Barker.

From Years 3-17 no significant trend occurred in mean DFF of plants derived from either site. However, some significant variations in mean DFF occurred from year to year. For the Mt Barker mixture, plants from Year 16 seed differed significantly in mean DFF from both Year $15(\mathrm{P} \leq 0.01)$ and Year $17(\mathrm{P} \leq 0.001)$, while plants from Year 12 and Year 13 seed also differed significantly $(\mathrm{P} \leq 0.05)$. Similarly, for the Nabawa mixture, plants from Year 4 seed differed significantly in mean DFF to those from both Year $3(\mathrm{P} \leq 0.001)$ and Year $5(\mathrm{P} \leq 0.001)$, and those from Year 10 seed also differed significantly from Year $11(\mathrm{P} \leq 0.01)$. For the Nabawa mixture, the betweenseason differences in mean DFF were partially explained by the significant correlation $(\mathrm{r}=0.57, \mathrm{P} \leq 0.05)$ with growing season length. There was no such correlation at $\mathrm{Mt}$ Barker. However, in this case, a significant correlation $(\mathrm{r}=0.56, \mathrm{P} \leq 0.05)$ was found between mean DFF and May-October rainfall. 


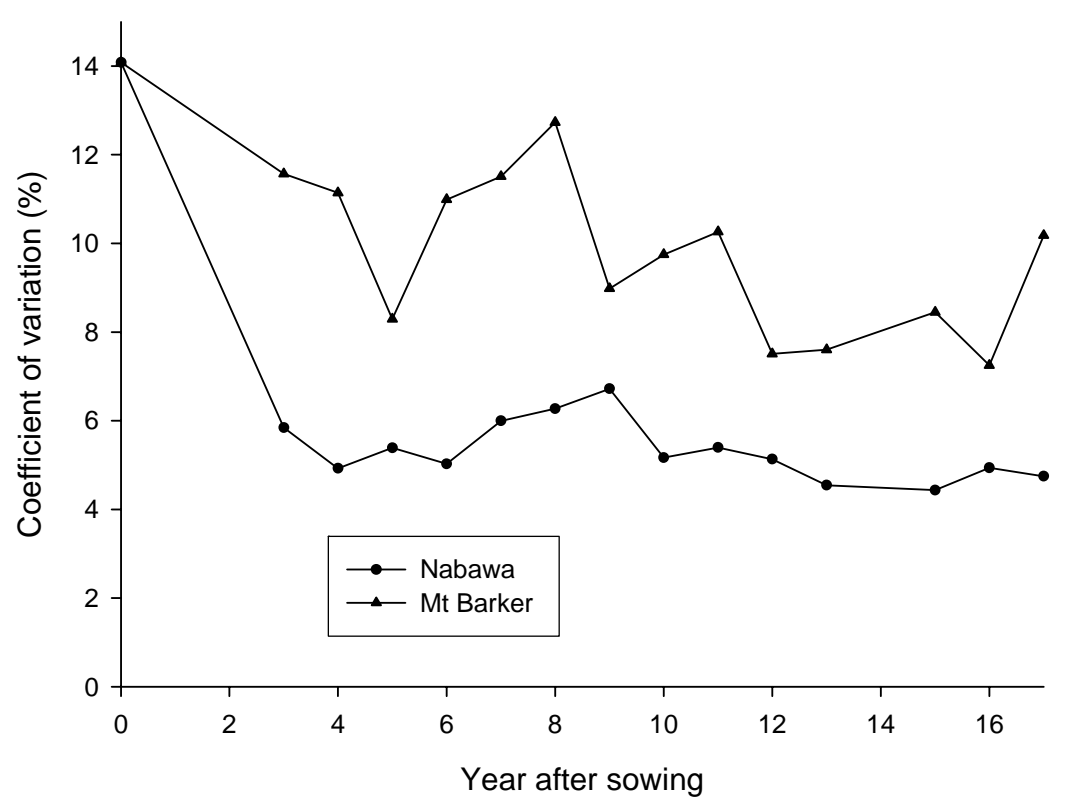

Figure 3. Coefficient of variation for days to first flowering at Shenton Park in 1995 from seed sampled each year from a bulk hybrid population sown in 1978 at Nabawa and Mt Barker.

Coefficient of variation for DFF was much greater in plants derived from $\mathrm{Mt}$ Barker seed than from Nabawa throughout the trial period (Figure 3). There was a significant negative trend in coefficient of variation for DFF between plants from the original bulk hybrid population and the Year 17 populations from both Mt Barker $(\mathrm{P} \leq$ $0.01)$ and Nabawa $(\mathrm{P} \leq 0.05)$. For the Mt Barker mixture, there was also a significant $(\mathrm{P}$ $\leq 0.05)$ negative trend between Years 3 to 17 . There was no such trend for the Nabawa mixture.

\section{Discussion}

Evolution in bulk hybrid populations

In this study flowering time was used as the major indicator of evolutionary change. It shows that from the one highly variable original bulk hybrid population, 2 quite different populations, in terms of flowering time, evolved over 17 years at the 2 sites. Furthermore, most of this evolution occurred within just 3 seasons. Had it been possible to use seed from the first 2 seasons, it is likely that even more rapid divergence would have been observed. Nichols (2004) conducted other studies with these populations and observed changes at one or both sites in population means for 20 other characters, while population variability declined in 11 characters. Although changes in fitness per se were not measured in this experiment, the ability to persist against competition from other genotypes is in itself a measure of relative fitness.

No bulk hybrid population studies have previously been conducted with subterranean clover. However, bulk hybrid studies have been conducted with other self-pollinated species. Allard (1988) describes directional changes in the means of a range of characters over 60 generations in a barley bulk hybrid population. He noted these generally contributed to higher reproductive capacity. Other barley bulk hybrid studies have measured directional selection for particular traits, including resistance to powdery 
mildew (Danquah and Barrett, 2002) and changes in frequency of hordein alleles (Ibrahim et al. 1996). Changes in adaptation to differing tillage systems (Hwu and Allen 1992) have also been reported in bulk hybrids of wheat.

Importance of flowering time

The results of this study clearly demonstrate the importance of appropriate flowering time for adaptation of subterranean clover and other annual legumes to particular environments. At the short growing season site of Nabawa, there was strong selection pressure for early flowering genotypes, whereas midseason and late flowering genotypes were favoured in the longer growing season environment of Mt Barker. However, the wider range of DFF at Mt Barker indicates that selection pressure for optimum DFF was not as strong as at Nabawa. While mean DFF did not change further over time, variability continued to decline at Mt Barker, suggesting that even after 17 seasons, selection was still occurring against both earlier and later flowering genotypes. Correlations between length of growing season and flowering time in subterranean clover have previously been shown by Morley et al. (1962), Piano (1984), Cocks (1992), Piano et al. (1993, 1996), Dear et al. (2001), Pecetti and Piano (2002) and Nichols (2004). The finding that DFF at Nabawa was more uniform than at Mt Barker conforms with the ecotype studies of Piano et al. (1993, 1996), Ehrman and Cocks (1996) and Pecetti and Piano (2002), who found greater uniformity of DFF in populations from drier environments.

Use of bulk hybrids for selecting adapted genotypes of annual pasture species Use of the bulk hybrid method for breeding adapted genotypes of subterranean clover was first proposed by Cocks et al. (1982). This study suggests it is likely to yield plants well adapted to test environments. While adapted genotypes can be selected after just 3 seasons, further adaptive fine-tuning occurs with increased homozygosity. The method is also applicable to breeding other self regenerating annual pasture species.

The success of the method hinges on parents containing genes for desirable characters, sites being representative of target environments and trial management being representative of typical farm practice. It is cheaper to operate and takes no longer than traditional plant breeding methods to produce homozygous lines and requires minimal land and few inputs following sowing. It also allows selection for regional adaptation at sites distant from a main breeding centre. The main disadvantage is that the breeder has limited control over the direction of selection. Selection is also likely to favour characters relating to survival rather than productivity per se. However, it is possible to impose treatments on populations to select for resistance or tolerance to pests, diseases or herbicides or particular grazing or cropping practices. Judicious site selection also allows selection of plants adapted to soil constraints such as salinity, waterlogging, low or high $\mathrm{pH}$ or low nutrient status.

The method has been adopted as an additional means of breeding subterranean clover in the National Annual Pasture Legume Improvement Program to those outlined by Nichols (1993) and Nichols et al. (1994). $F_{2}$ seed from over 600 crosses was sown in 1998 at 6 contrasting sites in southern Australia (Wongan Hills, Condingup, Manjimup and Wundowie in Western Australia, Hamilton in Victoria and Wagga Wagga in New South Wales). Seed has recently been harvested from each site and resultant genotypes will be characterised for a range of important agronomic characters, prior to consideration for wider scale field testing. 


\section{Acknowledgements}

The project was initiated by Drs Bill Collins, Clive Francis, John Gladstones and the late Reg Rossiter. The senior author was the recipient of an International Wool Secretariat Postgraduate Scholarship. Mr. Kevin Foster collected and maintained seed samples. Dr Bill Bowden helped develop the soil moisture balance model.

\section{References}

Allard RW (1988) Genetic changes associated with the evolution of adaptedness in cultivated plants and their wild progenitors. Journal of Heredity 79, 225-238.

Cocks PS (1992) Evolution in sown populations of subterranean clover (Trifolium subterraneum L.) in South Australia. Australian Journal of Agricultural Research 43, 1583-1595.

Cocks PS, Craig AD, Kenyon RV (1982) Evolution of subterranean clover in South Australia. II. Change in genetic composition of a mixed population after 19 years grazing on a commercial farm. Australian Journal of Agricultural Research 33, 679-695.

Danquah EY, Barrett JA (2002) Evidence of natural selection for disease resistance in Composite Cross Five (CCV) of Barley. Genetica 115, 195-203.

Dear BS, Virgona J, Sandral GA, Swan AD, Orchard BA (2001) Effect of companion perennial grasses and lucerne on seed yield and regeneration of subterranean clover in two wheatbelt environments. Australian Journal of Agricultural Research 52, 973-983.

Ehrman T, Cocks PS (1996) Reproductive patterns in annual legume species on an aridity gradient. Vegetation 122, 47-59.

Hwu K, Allen RE (1992) Natural selection effects of wheat populations grown under contrasting tillage systems. Crop Science 32, 605-611.

Ibrahim KM, Hayter JBR, Barrett JA (1996) Frequency changes in storage protein genes in a hybrid bulk population of barley. Heredity 77, 231-239.

Morley FHW, Davern CI, Rogers VE, Peak JW (1962) Natural selection among strains of Trifolium subterraneum. In 'The evolution of living organisms.' Symposium of the Royal Society of Victoria pp. 81-190. (Melbourne University Press: Melbourne)

Nichols PGH (1993) An agro-ecological approach to breeding subterranean clover. Proceedings of the XVII International Grassland Congress, Palmerston North, NZ. Vol 1: 453-454.

Nichols PGH (2004) Evolution in sown mixtures of subterranean clover (Trifolium subterraneum L.). PhD Thesis, University of Western Australia.

Nichols PGH, Collins WJ, Gillespie DJ, Barbetti MJ (1994) Developing improved varieties of subterranean clover. Western Australian Journal of Agriculture 35, 60-65.

Nichols PGH, Collins WJ, Barbetti MJ (1996) Registered cultivars of subterranean clover - their characteristics, origin and identification. Agriculture Western Australia, Bulletin No. 4327, South Perth, Western Australia.

Pecetti L, Piano E (2002) Variation of morphological and adaptive traits in subterranean clover populations from Sardinia (Italy). Genetic Resources and Crop Evolution 49, 189-197.

Piano E (1984) Preliminary observations on the structure and variability of Sardinian populations of subterranean clover. Genetica Agraria 38, 75-90. 
Piano E, Spanu F, Pecetti L (1993) Observations on the structure and variability of populations of subterranean clover from Sicily, Italy. Euphytica 68, 43-51.

Piano E, Pecetti L, Carroni AM (1996) Climatic adaption in subterranean clover populations. Euphytica 92, 39-44.

Prescott JA (1934) Single value climatic factors. Transactions of the Royal Society of South Australia 58, 48-61.

Sandral GA, Dear BS, Brennan J, Ewing MA (1997) The economic value of investment in annual plant improvement for cropping systems of Australia. Report to the Grains Research and Development Corporation, Canberra, Australia.

Suneson CA (1956) An evolutionary plant breeding method. Agronomy Journal 48, 188-190. 